\title{
A representação do mecanismo cognitivo de Sherlock Holmes em "A Noiva Abominável"
}

\author{
Maria Ignês Carlos Magno \\ Doutora em Ciências da Comunicação pela Escola de Comunicaşões e Artes da Universidade de São \\ Paulo (ECA-USP). Professora do mestrado em Comunicação da Universidade Anhembi Morumbi. \\ E-mail: unsigster@gmail.com \\ Letícia Kuhl \\ Psicopedagoga e mestranda do Programa de Pós-Graduação em Comunicação Audiovisual da \\ Universidade Anhembi Morumbi. \\ E-mail: leticiakuhl@hotmail.com
}

Resumo: O objetivo deste artigo é investigar e analisar o mecanismo cognitivo de Sherlock Holmes na narrativa do episódio "A Noiva Abominável", exibido pela BBC, que sintetiza todos os processos usados durante a série por meio da definição de sua personalidade, caracterizada como a de um sociopata altamente funcional. A função da memória para a resolução dos crimes; o motivo de seu ceticismo diante de fatos que não podem ser comprovados cientificamente; a inteligência acima da média e a capacidade para observar e imaginar além daquilo que é obvio; a prática de meditação e uso de drogas alucinógenas também são analisados. Para esta discussão serão apresentados autores como Ivan Izquierdo, com seu referencial sobre o mecanismo da memória, além de Umberto Eco e Thomas Sebeok, com a teoria de abdução, essencial para o entendimento das estratégias investigativas de Sherlock Holmes.

Palavras-chave: Sherlock Holmes; série televisiva; cognição.
Abstract: The main objective of this article is to investigate and analyze the cognitive mechanisms of Sherlock Holmes during the narrative of the episode "The Abominable Bride" broadcast by BBC, which synthesizes all processes used during the series by defining his personality as a high-functioning sociopath. The role of his memory to solve crimes, the real motive behind his skepticism when faced by facts that cannot be scientifically proven, his above average intelligence, his capacity to observe and imagine beyond the obvious, the practice of meditation and the use of hallucinogen drugs are also analyzed in this study. For this discussion we will use authors like Ivan Izquierdo and his framework about the memory mechanism, as well as Umberto Eco and Thomas Sebeok and the Theory of Abduction, which are essential to understand the investigative strategies of Sherlock Holmes.

Keywords: Sherlock Holmes; television series; cognition.
Recebido: 21/03/2018

Aprovado: 21/03/2018 
comunicação \& educação • Ano XXIII • número 1 • jan/jun 2018

\section{INTRODUÇÃO}

O personagem Sherlock Holmes desperta inquietação no público desde as primeiras publicações de suas aventuras na Revista Strand até as releituras cinematográficas e televisivas feitas durante os séculos XX e XXI. O detetive, com seu comportamento e seus métodos investigativos peculiares, poderia facilmente ser categorizado em nosso imaginário como um super-herói. O principal questionamento é: como um homem comum consegue solucionar mistérios extraordinários, de grande complexidade, apenas com seu mecanismo cognitivo? O episódio "A Noiva Abominável" retrata o lado humano e vulnerável de Sherlock, mostrando suas potencialidades e vulnerabilidades nas práticas cotidianas.

Esse episódio foi transmitido em $1^{\circ}$ de janeiro de 2016 como um especial de ano novo produzido pela British Broadcasting Corporation (BBC). Após sua transmissão televisiva, foi exibido em mais de duzentas salas de cinema em todo o mundo. Dessa vez (diferentemente dos episódios regulares ambientados no século XXI) a série retrata uma história de investigação do detetive na Era Vitoriana, trazendo a referência da época vivida pelo autor dos livros de Sherlock, Sir Arthur Conan Doyle (1859-1930). Assim como todas as histórias da série televisiva da BBC, esse episódio foi baseado em alguns contos originais de Sherlock Holmes ${ }^{1}$, de forma que o conceito de intertextualidade entre a obra literária e o audiovisual pode ser observado.

Considerando então, com Bakhtin e Kristeva, a questão do dialogismo e intertextualidade já na composição do próprio texto (literário), é possível compreender o grau da polifonia na adaptação da narrativa literária para o cinema. Pode-se, inclusive, chegar a dizer, de novo com Stam (2008: 25), que "a adaptação, neste sentido, consiste na ampliação do texto-fonte através destes múltiplos intertextos [pintura, música, recursos audiovisuais e digitais]. ${ }^{2}$

No caso da série Sherlock, da BBC, a adaptação não de um, mas de vários contos em um mesmo episódio elevam a qualidade da narrativa de maneira significativa, pela produção técnica e pela história que se expande pelo próprio recurso da intertextualidade.

Os contos adaptados são: The five orange pips, em que o pai da personagem principal recebe um envelope com cinco sementes de laranja com as iniciais KKK (Ku Klux Klan); The Musgrave Ritual, em que Sherlock considerava abominável o aspecto da esposa do protagonista; The final problem, no qual Sherlock e

1. DOYLE, Arthur Conan. Sherlock Holmes: the ultimate collection. Los Angeles: Enhanced Media, 2016. Kindle Edition.

2. RIBAS, Maria Cristina Cardoso. Literatura e Cinema: um breve passeio teórico pelos bosques da adaptação. Revista Alceu, v. 14, n. 28, p. $117-128,2014$, p. 121-122. seu arqui-inimigo Moriarty travam uma luta à beira do precipício das cachoeiras de Reichenbach, sucedendo-se a queda de ambos; e The adventure of the Sussex Vampire, em que a esposa do personagem principal é flagrada ao lado da cama do filho, com uma aparência fantasmagórica e lábios muito vermelhos.

A ideia de propor para essa resenha o episódio "A Noiva Abominável” da série televisiva Sherlock deu-se por vários motivos: um deles é o interesse que as séries e suas variadas temáticas têm despertado nos jovens atualmente; outro é a possibilidade de discutir os processos de adaptação e representação de uma 
obra literária para os mais diferentes meios de comunicação, seja o rádio, o cinema, a televisão ou o game, atualizando-a constantemente. E, principalmente, a motivação é mostrar como um produto veiculado pelo mais popular de todos os meios de comunicação, a televisão, abordou uma das características centrais da personagem de Artur Conan Doyle: os mecanismos cognitivos de Sherlock Holmes.

\section{A PERSONALIDADE DE SHERLOCK HOLMES}

No início do episódio, há uma sequência de cenas dos três anos de temporada, (2010, 2012 e 2014, até então), promovendo para o espectador que não acompanhou a série até esse especial um flashback relevante para o entendimento da narrativa. No caso da série e desse episódio, ambos se enquadram na configuração do cinema clássico hollywoodiano, pois nesse estilo os personagens são definidos (como todos da série: Sherlock como detetive, Watson como médico e fiel parceiro de Sherlock, Lestrade como policial da Scotland Yard, entre outros) e todos têm em comum o propósito de ajudar Sherlock a resolver os crimes que necessitam do seu método de investigação para serem resolvidos.

as personagens entram em conflito com outras personagens ou com as circunstâncias externas. A história finaliza com uma vitória ou derrota decisiva, a resolução do problema e a clara consecução ou não consecução dos objetivos. O principal agente causal é, portanto, o personagem como um indivíduo distinto, dotado de um conjunto evidente e consistente de traços, qualidades e comportamentos. ${ }^{3}$

Na narrativa clássica, a ligação entre causa e efeito é o elemento que desencadeia a construção da fábula. Todos os cenários são fiéis às suas características originais - como as ruas de Londres na Era Vitoriana, que são o palco dos primeiros assassinatos cometidos pela Noiva Abominável, ou seja, esse cenário tem uma função dentro da fábula. O syuzhet ${ }^{4}$, ordem temporal que situa os eventos da história, é reproduzido primeiro pelo cronômetro do início do episódio, e durante a narrativa o ponto temporal que estabelece os acontecimentos são os crimes cometidos pela noiva, o relato da cliente que procura Sherlock para proteger seu marido do fantasma da Noiva Abominável e o conflito emocional de Sherlock, causado pela impotência de criar hipóteses logo após um crime e pelo uso de drogas, estado esse que se estabiliza somente no final do episódio.

No minuto final do flashback, Sherlock atira em um homem, cometendo um assassinato, e grita, definindo sua personalidade como a de um sociopata altamente funcional. Depois embarca para o exílio pelo crime que cometeu, mas, por conta de novas ameaças de Moriarty, ele retorna - o que culmina na cena do avião de Sherlock pousando.

Os atos da personagem não condizem com as patologias definidas pela Associação Americana de Psiquiatria (APA) estabelecidas na última edição do
3. BORDWELL, David. O cinema clássico hollywoodiano: normas e princípios narrativos. In: RAMOS, Fernão Pessoa (org.). Teoria contemporânea do cinema: documentário e narratividade ficcional. São Paulo: Senac, 2005. v. 2. p. 278-279.

4. Syuzhet é a totalidade de situações em ordem sequencial representadas na obra áudio visual. 
Manual diagnóstico e estatístico de transtornos mentais. Conforme o DSM-55, para ser qualificado como um sociopata funcional Sherlock deveria apresentar os seguintes sintomas:

1) Impulsividade predominante ou incapacidade de seguir planos traçados para o futuro. Se Sherlock apresentasse essas características, seria incapaz de planejar as estratégias para solucionar, no caso desse episódio, os assassinatos cometidos pela Noiva Abominável;

2) Histórico constante de lutas corporais e agressões verbais violentas. $\mathrm{Na}$ série e nesse especial as lutas de Sherlock são frutos de sua inteligência, argumentando sobre os atos de seus inimigos. Somente no último momento há um breve confronto com Moriarty na cachoeira de Reichenbach;

3) Desrespeito irresponsável pela própria segurança ou pela segurança alheia. Durante a narrativa desse especial, Sherlock planeja deixar o personagem ameaçado de morte em segurança, contrariando essa patologia;

4) Fracasso em manter um comportamento laboral consistente. O detetive sempre exerceu a função de investigador;

5) Tendência para enganar indicada por mentir compulsivamente, distorcer fatos ou ludibriar os outros para obter credibilidade, vantagens pessoais ou prazer. Sherlock não é um mentiroso compulsivo: ele manipula fatos para obter informações que possam ajudá-lo em suas investigações;

6) Dissociabilidade familiar marcada por desrespeito ou desapreço. Nesse episódio Sherlock tem uma discussão com seu irmão mais velho, inclusive demonstrando certa preocupação com sua saúde, pois Mycroft come compulsivamente.

Portanto a definição de sociopata funcional não qualifica a personalidade e, consequentemente, os atos de Sherlock.

Para Cupertino $^{6}$, características como inteligência acima da média somada a flexibilidade e fluência de pensamento; capacidade de abstração para fazer associações; produção ideativa, compreensão e memória elevadas; grande curiosidade a respeito de situações e eventos; envolvimento em muitas atividades exploratórias; capacidade de enriquecimento com situações problema, de seleção de respostas e de busca de soluções para resoluções difíceis ou complexas são frequentemente apresentadas por indivíduos superdotados.

No cenário social da vida de Sherlock podemos conceituá-lo como portador

5. A M E R I C A N ASSOCIATION. DSM-5: Manual diagnóstico e estatístico de transtornos mentais. 5. ed. Porto Alegre: Artmed, 2014. p. 659.

6. CUPERTINO, Christina Menna Barreto. Um olhar para as altas habilidades: construindo caminhos. São Paulo: FDE, 2008.

7. AMERICANPSYCHIATRIC ASSOCIATION, op. cit., p. 52. da Síndrome de Asperger. Segundo o DSM-5 $5^{7}$, os sintomas do Asperger fazem parte do Transtorno do Espectro Autista e se manifestam como: a) falha no desenvolvimento de relações com pares de sua idade; b) falta de interesse espontâneo em dividir experiência com os outros e ausência de reciprocidade emocional e social.

Esses dois sintomas explicam porque Watson é seu único amigo e, ainda assim, quando o médico tenta fazer alguma abordagem mais íntima, Sherlock desvia o assunto. Este apresenta o olhar fixo e peculiar, como quando ouve o relato dos assassinatos cometidos pela Noiva Abominável, e tem dificuldade de ajuste à 
aproximação física -limita-se a um simples aperto de mão quando percebe que alguém tenta outro tipo de proximidade -, fatos que nos permitem definir a personalidade e os atos de Sherlock como os de um adulto superdotado com a excepcionalidade da Síndrome de Asperger.

\section{A REPRESENTAÇÃO CINEMATOGRÁFICA DA METODOLOGIA CIENTÍFICA DE SHERLOCK}

Após o flashback das cenas da série, ambientadas no século XXI, um cronômetro com a data de 2014 começa uma contagem regressiva até um ano indefinido entre 1880 e 1890. O início desse episódio é idêntico ao primeiro da série, no qual Watson, interpretado por Martin Freeman, assim como na cena ambientada na atualidade, surge narrando sua experiência na guerra - neste caso, a Segunda Guerra Anglo-Afegã (1878-1880) - e seu retorno para Londres. Esse episódio se passa na Era Vitoriana, elemento temporal que pode causar estranheza ao espectador que não tem ciência sobre esse capítulo especial, pois a série da BBC retrata Sherlock no século XXI. A época é retratada a partir de seus elementos característicos: carruagens, roupas de época e linguagem formal.

Watson, que procura um novo lugar para morar, encontra-se por acaso com um amigo que diz conhecer um homem que procura o mesmo. Esse amigo leva Watson até Sherlock, que está no necrotério, açoitando um cadáver. Nesse momento Sherlock faz sua primeira abdução, ao descrever com detalhes a situação de Watson, de onde ele acabara de chegar e a função que tinha. Logo informa o endereço do apartamento em que estava interessado, intimando Watson a encontrá-lo lá.

A cena é interrompida pela vinheta que, como na introdução, situa o espectador na Era Vitoriana, com seus elementos de época, compondo novamente a configuração espacial da fábula e sobrepondo em alguns momentos cenas do episódio. A vinheta conecta-se com o começo da narrativa, que focaliza a revista Strand nas mãos de um vendedor, na qual Sir Conan Doyle publicava as aventuras de Sherlock, quase sempre narradas por Watson - outra intertextualidade com a obra literária. Watson segue com Sherlock numa carruagem para a Baker Street 221B e, na sequência, as personagens principais são apresentadas.

Lestrade, detetive da Scotland Yard, faz o relato sobre os assassinatos que a Noiva Abominável cometeu mesmo depois de morta, iniciando nesse momento o sistema narrativo da história. Para Esquenazi ${ }^{8}$, "o sistema narrativo de qualquer história policial é o resultado da trama de duas narrativas: a primeira é a do crime; e, a segunda, da investigação". A relação entre a trama e a investigação estabelecerá as características peculiares da série.

Durante o relato de Lestrade, a câmera se aproxima do cachimbo que Sherlock acende, e imediatamente acontece a transição para o cano do revólver que a Noiva Abominável está usando para atirar nos homens que passam pela rua. A câmera volta para Sherlock, que pede uma pausa no relato de Lestrade,
8. ESQUENAZI, Jean-Pierre. As séries televisivas. Lisboa: Edições Texto \& Grafia, 2011. p. 131. 
e então se afasta novamente, fazendo um movimento em $360^{\circ}$ e mostrando Sherlock sentado na poltrona de seu apartamento; depois volta-se para a rua, mostrando os homens como se estivessem parados no tempo, e retorna para o cenário da sala do apartamento, montada de maneira teatral no meio da rua onde aconteceram os assassinatos. A câmera foca novamente em Sherlock e, quando Lestrade responde à sua pergunta, o plano se abre; então o espectador percebe que as personagens voltaram para o cenário interno do apartamento. Durante a resposta, surge a cena fantasmagórica da noiva cometendo suicídio, incorporando uma mistura de gêneros: o policial e o de terror.

Segundo Esquenazi ${ }^{9}$, "a mistura dos gêneros, sem se tornar uma palavra de ordem, passou para os meios seriais".

Depois dessa sequência, Sherlock segue para o necrotério acompanhado de Watson e Lestrade, onde encontram dr. Hooper (Molly Hooper, na série ambientada no século XXI, é a médica legista da série; nesse especial ela aparece disfarçada como dr. Hooper, um médico, já que na Era Vitoriana mulheres não podiam exercer essa profissão). Sherlock pede para ver o cadáver da noiva, que está acorrentada, e pergunta em tom alterado quem teria feito tamanha tolice ao prender um cadáver. Anderson, que interpreta o assistente da legista Hooper, discute com Sherlock e diz que o fez para a segurança de todos, pois a noiva, mesmo morta, teria assassinado o ex-marido.

O mecanismo básico de pensamento de Sherlock parte do método científico, que justifica o ceticismo diante daquilo que não pode ser comprovado pela ciência. Para Konikkova ${ }^{10}$, Sherlock parte "da mais mundana das coisas: a observação [...] é preciso explorar os fundamentos mais básicos, a base de funcionamento de algo, aquilo que faz daquilo o que ele é". Primeiro Sherlock observa o crime, depois faz uma suposição, uma hipótese do que poderia ter acontecido, e então traça uma linha de investigação. Em seguida realiza a investigação, que pode ser flexível e ter a necessidade de ser revista por conta de tempo ou mudança de cenário. Por fim, chega à solução do crime.

Aprofundando o método científico de pensamento, podemos abordar o conceito da meta-abdução apresentado por Eco e Sebeok ${ }^{11}$, que é a base para a criação do conhecimento abdutivo. Ou seja, Sherlock parte de um conhecimento, já acomodado pela sua experiência significativa em investigação, e então agrega elementos imagéticos que são resultados da observação de suas práticas para, em seguida, construir sua linha de raciocínio, criando uma relação entre fatos comprovados e novas hipóteses. A metabdução

consiste em decidir se o universo delineado por nossas abduções de primeiro nível é o mesmo que o universo de nossa experiência. Em abduções hiper e hipocodificadas, esse metanível de inferência não é compulsório, uma vez que retiramos a lei de um estoque de experiência de mundo real já checado. Em outros termos, estamos autorizados pelo conhecimento mundano a pensar que, assegurado que a lei é a adequada, ela já pertence ao mundo de nossa experiência. Tratando-se de abduções criativas, não temos esse tipo de certeza. Estamos realizando uma verdadeira "suposição razoável" não apenas acerca da natureza do resultado (sua causa) como também acerca da enciclopédia (de modo que, 
se ocorre de a nova lei ser confirmada, nossa descoberta conduz a uma mudança de paradigma). Como veremos, a meta-abdução não é apenas decisiva em descobertas científicas "revolucionárias", mas também (e normalmente) em investigações criminais. ${ }^{12}$

Conforme citado acima, a abdução em primeiro nível é a prática imaginativa para construir uma circunstância diante de algo improvável, e a abdução hipercodificada é a criação automática ou semiautomática de uma hipótese, ou seja, o primeiro instante de pensamento criativo diante de uma circunstância. A abdução hipocodificada é um princípio a ser adotado e selecionado entre dois fatores para estabelecer uma regra. Neste caso, tratando-se de Sherlock, é a escolha que ele estabelece entre as hipóteses encontradas para planejar uma investigação.

Não há memória sem aprendizado, nem há aprendizado sem as experiências significativas. Izquierdo ${ }^{13}$ afirma que "a memória de curta duração estende-se desde os primeiros segundos ou minutos seguintes ao aprendizado até três a seis horas, o tempo que a memória de longa duração leva para ser construída". Sherlock tem sua memória preservada para aquilo que sua especialidade exige, descartando detalhes inúteis para seus processos cognitivos e facilitando, assim, a formulação de hipóteses para a solução de problemas.

Nesse episódio, Sherlock e Watson saem do necrotério numa carruagem, que está com os vidros molhados e embaçados. Uma música cria a atmosfera de suspense, e o espectador consegue perceber o desenquadramento da câmera, ou seja, o personagem sai do ângulo de visão, e nota-se somente a fisionomia preocupada de Sherlock. Esquenazi ${ }^{14}$ afirma que "o desequilíbrio contínuo da câmera [...] são [é] um equivalente visual da instabilidade dos protagonistas", como se mostra na sequência. Watson questiona Sherlock sobre as hipóteses para a solução dos crimes e, naquele momento, o detetive pensativo diz ao amigo que irá precisar mergulhar em águas muito profundas para construí-las, demonstrando um conflito emocional severo diante de uma das principais características do personagem: a de criar hipóteses de imediato, de maneira prática, logo após a observação ou o relato de um crime, de modo racional.

Em seguida, Watson narra a passagem de sete meses: Sherlock e Lestrade discutem sobre os cinco assassinatos cometidos pela Noiva Abominável e Sherlock ironiza Lestrade por acreditar novamente que um cadáver cometeu os crimes. Quando Sherlock nota a falta de Watson, segue-se uma cena que mostra o médico em casa discutindo com sua empregada, que lhe entrega um bilhete de Holmes. A comunicabilidade do que está escrito no bilhete é mostrada ao espectador com o efeito de uma animação, que é repetida quando Sherlock e Watson vão encontrar Mycroft num clube exclusivo, onde só a língua de sinais é permitida em público - nesse caso a animação revela o que as personagens estão gesticulando.
12. Ibidem, p. 229

13. IZQUIERDO, Ivan Memória. Porto Alegre: Artmed, 2014. p. 102. 14. Op. cit., p. 124. 
Mycroft pede que Sherlock atenda ao pedido de uma cliente. Na cena posterior estão a cliente, Sherlock e Watson no apartamento, todos ouvindo o relato desta, que é um elemento de motivação composicional.

Um segmento clássico não é uma entidade lacrada. Ele é especial e temporalmente fechado, mas causalmente aberto, operando para fazer avançar a progressão causal e abrir novos desenvolvimentos. O padrão desse "momentum para a frente" é bastante codificado. A sequência montada tende a funcionar como um resumo transacional, comprimindo um desenvolvimento causal único. ${ }^{15}$

A progressão causal que ocorre na sequência é um desenvolvimento narrativo em paralelo, escopo para a solução do caso da Noiva Abominável, que até o momento seguia apenas com um único desdobramento. Sherlock acreditava que criminosos se aproveitavam das notícias sobre os assassinatos da noiva e então cometiam crimes com as mesmas características. Em seguida há um relato, que não é narrado, mas mostrado como um acontecimento paralelo: a cliente, esposa da personagem ameaçada de morte, acorda no meio da noite sem seu marido na cama e vai procurá-lo no jardim. A cena é escura e nebulosa. A música cria a atmosfera de suspense e terror, dando destaque ao vulto da Noiva Abominável sussurrando uma música e ameaçando outra personagem - o que traz novamente a menção ao filme de gênero, neste caso, o de terror.

No fim da sequência, o jardim em forma de labirinto é mostrado de um plano superior, que serve de transição para as mãos de Sherlock, e então a narrativa volta ao apartamento.

Sherlock traça uma estratégia para salvar a personagem e revelar o mistério da Noiva Abominável. Ele e Watson seguem, à noite, para a residência de sua cliente, que foi instruída a deixar seu marido sozinho em um dos cômodos. Os dois se escondem na parte externa da casa, e então surge no jardim o fantasma da noiva. Começa uma sequência do gênero dos filmes de ação e suspense, criada pela música e pela sucessão de fatos num curto período, de apenas dois minutos, quando Holmes e Watson correm em direção ao fantasma.

A dificuldade dos dois para entrar na casa obriga-os a quebrar uma janela. Holmes sobe as escadas no escuro ao ouvir o grito de sua cliente diante do marido morto com uma adaga. Sherlock tenta identificar o rastro de sangue, e Watson sente-se ameaçado pelo fantasma, de modo que o detetive, alterado, afirma que fantasmas não existem.

Segundo Esquenazi ${ }^{16}$, "a mistura de gêneros, quando é assumida com segurança e ousadia, parece conduzir quase mecanicamente a uma reflexividade que ilumina toda a série". A sequência descrita desencadeia um dos pontos principais da narrativa: aquele em que Sherlock tem de enfrentar seus próprios fantasmas. Lestrade está na cena do crime conversando com Sherlock e chama sua atenção para um bilhete que teria sido deixado após a constatação do assassinato: uma etiqueta presa à adaga, no peito do cadáver, com a frase "miss $m e$ ?", expressão usada frequentemente pelo arqui-inimigo de Holmes, Moriarty.

15. BORDWELL, op. cit., p. 282. 16. Op. cit., p. 136.
A câmera enquadra Sherlock, levando o espectador a perceber outro lado do detetive, dessa vez emocionalmente abalado. 


\section{MEDITAÇÃO, DROGAS E ALUCINAÇÕES}

Sherlock faz uso frequente da meditação para acessar seu "palácio da mente”, uma técnica de memorização que agrega estruturas ao conteúdo. Na cena em que medita no apartamento, o detetive recorda a leitura de algumas notícias de diferentes jornais para fazer a recapitulação dos fatos, descartando aquelas que não têm importância para ele. Em seguida, faz uso de cocaína injetável. Então começa a alucinar:

as alucinações que trataremos aqui são essencialmente retornos compulsivos a uma experiência passada. Mas, aqui, em contraste com os flashbacks, às vezes comoventes, mas essencialmente triviais, das convulsões do lobo temporal é o passado significado - estimado ou terrível - que volta a assombrar a mente: experiências de vida tão carregadas de emoções que produzem uma impressão indelével no cérebro e o compelem à repetição. As alucinações com fantasmas - espíritos de mortos que voltam - são especialmente associados à morte violenta e culpa. ${ }^{17}$

Sherlock alucina com Moriarty, seu arqui-inimigo, que supostamente estaria morto desde que caiu das cachoeiras de Reichenbach. Isso o desperta da meditação, provocando-o a respeito do caso da Noiva Abominável.

A cenografia treme em alguns momentos, mostrando a perturbação de Sherlock com Moriarty, que está armado. Moriarty suicida-se, mas não morre, causando horror em Sherlock, que não entende como ele ainda está vivo. Moriarty repete frases que Sherlock usa no cotidiano, e então há um grande tremor na cenografia, novamente com o artifício do desenquadramento da câmera.

A sequência seguinte remete o espectador à série ambientada no século XXI, retomando a mesma cena que se passa antes da contagem regressiva no início, com o retorno do avião de Sherlock. Os personagens principais, Watson, sua esposa Marie e Mycroft, entram no avião, e Sherlock acorda emocionalmente confuso, relatando o que tinha vivido momentos antes, na Era Vitoriana, com o caso da noiva e o retorno de Moriarty.

Depois de uma longa discussão com seu irmão sobre o uso de drogas e de ouvir a voz de Watson perguntando se ele havia usado cocaína ou morfina, Sherlock acorda em seu apartamento na Era Vitoriana, instável, e conta para Watson o que tinha vivido no século XXI, dentro do avião. Essa desordem temporal causa uma ambiguidade na memória do personagem e no entendimento do espectador.

Sherlock recebe um bilhete de Marie, que supostamente está correndo perigo. Eles a encontram numa igreja, onde ocorre uma reunião. As roupas e o ambiente remetem a uma metáfora da Ku Klux Klan. Então Sherlock entra na sala e todos o observam. Ele começa a compreender o crime, que foi arquitetado por todas as mulheres que sofreram abusos dos homens assassinados e que, neste momento, fazem parte do movimento sufragista.

Enquanto Sherlock conversa com as mulheres, uma noiva chega perto dele, e quando levanta o véu, Moriarty revela-se. Outra vez Sherlock acorda no século XXI e procura, com a ajuda das outras personagens, registros do caso da noiva
17. SACKS, Oliver. A mente assombrada. São Paulo: Cia das Letras, 2013. p. 208-209. 
na Era Vitoriana, provocando mais uma desordem temporal. Essas desordens temporais se seguem até o último momento do episódio, quando Watson questiona Sherlock sobre o futuro e, por conta de sua inteligência acima da média e alta capacidade criativa, o detetive detalha todas as invenções experimentadas por ele no século XXI.

\section{CONCLUSÃO}

Considerando as características de personalidade e os atributos cognitivos de Sherlock - sendo um deles a superdotação (inteligência e capacidade criativa acima da média, de acordo com Cupertino ${ }^{18}$ ) -, associados à Síndrome de Asperger (Transtorno do Espectro Autista que explica a condição de socialização de Sherlock, segundo as patologias mencionadas no DSM-5 e abordadas no item referente à sua personalidade), e também o conceito da abdução aprofundado por Umberto Eco e Sebeok, apresentado na análise do método científico de seu pensamento para resolução dos crimes, observamos que Sherlock se torna um detetive notável por características cognitivas e sociais peculiares, como também pela capacidade de se atentar para e de considerar elementos e circunstâncias que não seriam notados por outros indivíduos sem essas particularidades.

\section{REFERÊNCIAS BIBLIOGRÁFICAS}

AMERICAN PSYCHIATRIC ASSOCIATION. DSM-5: Manual diagnóstico e estatístico de transtornos mentais. 5. ed. Porto Alegre: Artmed, 2014.

BORDWELL, David. O cinema clássico hollywoodiano: normas e princípios narrativos. In: RAMOS, Fernão Pessoa (org.). Teoria contemporânea do cinema: documentário e narratividade ficcional. São Paulo: Senac, 2005. v. 2. p. 278-282.

CUPERTINO, Christina Menna Barreto. Um olhar para as altas habilidades: construindo caminhos. São Paulo: FDE, 2008.

DOYLE, Arthur Conan. Sherlock Holmes: the ultimate collection. Los Angeles: Enhanced Media, 2016. Kindle Edition.

ECO, Umberto; SEBEOK, Thomas A. O signo de três. São Paulo: Perspectiva, 1991.

ESQUENAZI, Jean-Pierre. As séries televisivas. Lisboa: Edições Texto \& Grafia, 2011.

IZQUIERDO, Ivan. Memória. Porto Alegre: Artmed, 2014.

KONNIKOVA, Maria. Perspicácia. São Paulo: Elsevier, 2013.

RIBAS, Maria Cristina Cardoso. Literatura e Cinema: um breve passeio teórico pelos bosques da adaptação. Revista Alceu, v. 14, n. 28, p. 117-128, 2014.

SACKS, Oliver. A mente assombrada. São Paulo: Cia das Letras, 2013. 